\title{
Preoperative Imaging Modalities to Predict the Risk of Regional Nodal Recurrence in Well- Differentiated Thyroid Cancers
}

\author{
Mohammed K. AlNoury ${ }^{1}$ Saad M. Almuhayawi ${ }^{2} \quad$ Khalid B. Alghamdi ${ }^{2} \quad$ Khaled I. Al-Noury ${ }^{2}$ \\ ${ }^{1}$ Department of Otolaryngology Head and Neck Surgery, King \\ Abdulaziz University, Jeddah, Saudi Arabia \\ 2 Department of Otolaryngology, King Abdulaziz University, Jeddah, \\ Saudi Arabia \\ Address for correspondence Mohammed K. AlNoury, MD, \\ Department of Otolaryngology Head and Neck Surgery, King Abdulaziz \\ University, P.O. Box 35135, Jeddah-21488, Saudi Arabia \\ (e-mail: m_k_nouri@hotmail.com).
}

Int Arch Otorhinolaryngol 2015;19:116-120.

\begin{abstract}
Introduction Thyroid cancer incidence has increased in the previous 2 decades. Preoperative identification of lymph node metastasis is a suggested risk factor associated with recurrence following thyroidectomy.

Objectives We aimed to evaluate the accuracy of preoperative radiologic investigations of nodal status in determining the postoperative risk of regional nodal recurrence in cases of well-differentiated thyroid cancer.

Methods This is a case series. We retrospectively reviewed data, including preoperative ultrasonography and/or computed tomography results, on patients who underwent total thyroidectomy for thyroid cancer at our hospital between 2006 and 2012. Prognostic factors for predicting recurrence, including age, sex, tumor diameter, and nodal diameter, were evaluated.

Results Total thyroidectomy was performed on 24 male and 74 female patients (median age, 43 years). The median follow-up time was 21 months. Sixty-eight patients had papillary thyroid cancer, and 30 had follicular cancer. Nodal recurrence was evident in $30 \%$ of patients, and $4 \%$ of patients died. Identification of lymph node involvement during preoperative radiologic investigations was strongly prognostic for recurrence: $35.3 \%$ of patients with positive preoperative ultrasonography findings and $62.5 \%$ of

Keywords

- thyroid neoplasms

- recurrence

- ultrasonography

- computed tomography

- X-ray those with positive preoperative computed tomography findings had recurrence $(p=0.01)$.

Conclusions Preoperative identification of lymph node metastasis on radiologic studies was correlated with an increased risk of regional nodal recurrence in welldifferentiated thyroid cancer. Computed tomography was superior to ultrasonography in detecting metastatic nodal involvement preoperatively and is therefore recommended for preoperative assessment and postoperative follow-up.
\end{abstract}

\section{Introduction}

The overall increase in the incidence of thyroid cancer over the last 2 decades can largely be attributed to increases in the incidence of papillary thyroid cancer (PTC). In 2010, there were an estimated 44,670 new cases of thyroid cancer and 1,690 deaths in the United States. ${ }^{1}$ PTC and its follicular variant account for 80 to $90 \%$ of all primary thyroid cancers. Furthermore, follicular thyroid cancer and Hurthle cell cancers comprise 5 to $10 \%$, medullary thyroid cancer comprises received

August 19, 2014

accepted

November 4, 2014

published online

December 8, 2014
DOI http://dx.doi.org/

10.1055/s-0034-1396521. ISSN 1809-9777.
Copyright $\odot 2015$ by Thieme Publicações License terms

Ltda, Rio de Janeiro, Brazil
(®) $\Theta \circledast$ 
$5 \%$, and anaplastic cancer comprises less than $1 \%$ of all thyroid malignancies. ${ }^{2,3}$ Differentiated thyroid cancer (DTC) can occur at any age but the median age at diagnosis is 49 years, and the prevalence in women is 3 times greater than that in men. ${ }^{4}$

Cervical recurrence of PTC following thyroidectomy occurs primarily as regional lymph node (LN) metastasis, which occurs in up to $20 \%$ of patients with low-risk disease (men $\leq 40$ years old; women $\leq 50$ years old) and $59 \%$ of patients with high-risk disease (older patients). ${ }^{3,5-7}$ This type of locoregional cervical LN recurs within the first 10 years following an initial diagnosis in 15 to $30 \%$ of patients. ${ }^{6,8}$ Current surveillance strategies to identify locoregional or nodal recurrence primarily rely on serial serum thyroglobulin measurements assessed in combination with cervical ultrasonography (US) and image-guided fine needle aspiration cytology (FNAC) of suspicious lesions. ${ }^{9-11}$ Recently, certain number of antibodies have been developed against antigen to improve morphologic diagnostic performances. ${ }^{12}$

Several tumor-staging systems have been developed for DTC in an attempt to include factors with prognostic value to guide the appropriate intensity of treatment and surveillance. The most relevant factors include patient age, tumor size and extent, locoregional nodal involvement, and distant metastases, ${ }^{4}$ but there are few studies discussing preoperative factors that could predict nodal recurrence. Factors that may decrease recurrence rates include a more comprehensive surgery, better tumor definition afforded by more sensitive US techniques, and the use of routine cervical lymphadenectomy to remove LNs that could cause recurrence. ${ }^{13}$ Innovations in serology, histopathology, immunochemistry, and diagnosis through radiologic investigations provide us with better understanding to plan the management and follow-up of well-differentiated thyroid cancer.

The objective of the current study was to evaluate the accuracy of preoperative radiologic investigations of nodal status in determining the postoperative risk of locoregional nodal recurrence in patients with DTC.

\section{Materials and Methods}

\section{Patient Screening}

Following the hospital ethics committee approval, the prospectively maintained database from our tertiary hospital was reviewed. Ninety-eight patients met the inclusion criteria, which were as follows: (1) well-differentiated thyroid cancer, (2) preoperative radiologic investigations performed in our hospital, (3) patient operative report, and (4) a minimum follow-up of 12 months. Demographic data, preoperative and postoperative US and/or computed tomography (CT) scans, FNAC findings, and surgical pathology were evaluated. The operative and pathology reports were reviewed, and all patients were staged according to the current American Joint Committee on Cancer (AJCC) staging system according to the documented histopathologic findings. ${ }^{14}$ The clinical course was determined, and all patients who presented with recurrent disease were identified. Follow-up evaluation included a physical examination, a neck US examination, measurement of serum thyroglobulin levels, and the selective use of neck CT scanning, total body radioactive iodine (RAI) scanning, FNAC, and histopathology reports. Patients were considered to have cervical recurrence if they had any of the following: nodal disease on clinical examination; detection of recurrence by FNAC; or an interval increase in activity on serial RAI imaging that prompted treatment with RAI, ${ }^{13}$ and positive FNAC was considered as most definitive end point of nodal recurrence.

\section{Diagnostic Imaging Modalities}

US of the soft tissue of the neck was performed using a highresolution scanner. The preoperative and postoperative status of central and lateral neck compartments was determined according to the sonographic appearance of the thyroid, a description of the lesion, and the appearance of the LNs. Sonographic features suggestive of abnormal metastatic LNs include loss of the fatty hilus, a rounded rather than oval shape, hypoechogenicity, cystic change, calcifications, and peripheral vascularity. Some patients underwent contrastenhanced CT with a multidetector scanner with a reconstructed slice thickness of $3 \mathrm{~mm}$ for axial and coronal images. A $90-\mathrm{mL}$ dose of iodinated contrast medium was administered intravenously at a rate of $3 \mathrm{~mL} / \mathrm{s}$ using an automated injector. A 3-mL/s flush of normal saline solution was injected immediately after administration of the contrast medium to reduce artifacts induced in the subclavian vein. The scan delay was 40 to 60 seconds. Due to different treating surgical teams and collecting of data retrospectively, different patients received different radiologic investigation. Therefore, we divided the patients into different groups: patients who received US pre- and postoperatively and patients who received CT scan pre- and postoperatively.

\section{Operative Procedures}

Total thyroidectomy was performed in cases diagnosed with DTC by FNAC. In most cases, a prophylactic central node dissection (CND) was performed in patients with PTC and clinical stage NO neck. A therapeutic CND and/or lateral neck dissection was performed in patients with evidence of central and/or lateral neck LN metastasis at the time of the surgery. After surgery, all patients underwent thyroid-stimulating hormone suppression treatment with oral thyroxin for 6 weeks, followed by RAI therapy to improve outcome and tumor control.

\section{Statistical Analyses}

All statistical tests were performed using SPSS version 16 (IBM). Univariate statistical analysis and cross-tabulation were performed to determine the significance of each factor in predicting cervical recurrence in DTC. The chi-square test was used to calculate $p$ values, and $p<0.05$ was considered statistically significant.

\section{Results}

Between January 2006 and December 2012, 98 patients underwent total thyroidectomy for a diagnosis of welldifferentiated thyroid cancer. Patient demographics are 
AlNoury et al.

shown in - Table 1. The median age at diagnosis was 43 years. The median follow-up was 21 months from the time of the index operation. Cervical recurrence was defined as metastatic involvement of any cervical LN developing $\geq 6$ months after surgery. Cases of cervical recurrences were mainly isolated LNs. Of the 98 patients, 71 (72\%) patients underwent preoperative US, and 35 (36\%) underwent preoperative CT; 8 patients underwent both studies. Fifty-six patients had postoperative US, and 42 had postoperative CT scans.

An analysis of factors predicting local recurrence is shown in - Table 2. Positive LN recurrence was higher in men compared with women, although the difference did not reach statistical significance $(p=0.784)$. In addition, age, tumor size, and LN size were not significant risk factors for local recurrence ( $p=0.608, p=0.385, p=0.875$, respectively).

Positive LN status on US was not correlated with the prediction of recurrence. In contrast, positive or negative LN status as detected by CT was significantly correlated with postoperative locoregional recurrence ( $p=0.01$; - Table 3 ). The US and CT analyses demonstrated similar efficacy at detecting thyroid nodules, but differed significantly in their ability to accurately evaluate cervical LN involvement in recurrence, with CT outperforming US (-Table 4).

\section{Discussion}

PTC is the most common endocrine neoplasia with a tendency for local and regional metastasis. ${ }^{15}$ The prognostic impact of

Table 1 Patient demographics

\begin{tabular}{|c|c|}
\hline Characteristics & $\begin{array}{l}\text { Number of } \\
\text { patients (\%) }\end{array}$ \\
\hline \multicolumn{2}{|l|}{ Sex } \\
\hline Male & $24(24.5)$ \\
\hline Female & $74(75.5)$ \\
\hline \multicolumn{2}{|l|}{ Age (y) } \\
\hline$<60$ & $76(77.6)$ \\
\hline$\geq 60$ & $22(22.4)$ \\
\hline \multicolumn{2}{|l|}{ Histopathology } \\
\hline Papillary thyroid cancer & $68(70)$ \\
\hline Follicular cancer & $30(30)$ \\
\hline \multicolumn{2}{|l|}{ Tumor size $(\mathrm{cm})$} \\
\hline$\leq 2$ & $45(46)$ \\
\hline$>2$ & $53(54)$ \\
\hline \multicolumn{2}{|l|}{ Lymph node size $(\mathrm{cm})$} \\
\hline No nodal involvement & $35(36)$ \\
\hline$\leq 2$ & $47(48)$ \\
\hline$>2$ & $16(16)$ \\
\hline Recurrence & $29(30)$ \\
\hline Death & $4(4)$ \\
\hline
\end{tabular}

Table 2 Risk factors correlated with recurrence

\begin{tabular}{|c|c|c|}
\hline Risk factors & $\begin{array}{l}\text { No. of } \\
\text { patients with } \\
\text { recurrence (\%) }\end{array}$ & $p$ Value \\
\hline \multicolumn{3}{|l|}{ Sex } \\
\hline Male $(n=18)$ & $8(44.4)$ & \multirow[t]{2}{*}{0.784} \\
\hline Female $(n=56)$ & $22(39.3)$ & \\
\hline \multicolumn{3}{|l|}{ Age (y) } \\
\hline$\leq 60(n=58)$ & $22(37.9)$ & \multirow[t]{2}{*}{0.538} \\
\hline$>60(n=16)$ & $8(50)$ & \\
\hline \multicolumn{3}{|l|}{ Tumor size $(\mathrm{cm})$} \\
\hline$\leq 2(n=38)$ & $18(47.4)$ & \multirow[t]{2}{*}{0.385} \\
\hline$>2(n=36)$ & $12(33.3)$ & \\
\hline \multicolumn{3}{|l|}{ Lymph node size $(\mathrm{cm})$} \\
\hline $\begin{array}{l}\text { No nodal involvement } \\
(n=26)\end{array}$ & $10(38.5)$ & \multirow[t]{3}{*}{0.875} \\
\hline$\leq 2(n=36)$ & $14(38.9)$ & \\
\hline$>2(n=12)$ & $6(50)$ & \\
\hline
\end{tabular}

${ }^{\mathrm{a}}$ The chi-square test was used to measure $p$ values ( $p<0.05$ was considered significant by Fisher's exact tests).

cervical LN involvement has been investigated in many studies, but remains a controversial issue. ${ }^{16-18}$ Initial studies suggested that the presence of nodal metastasis had no effect in overall or disease-free survival, but this notion has been recently refuted. ${ }^{19}$ Patients with PTC with cervical LN metastasis at initial presentation are more susceptible to recurrence than those without LN involvement. ${ }^{16-18}$ The preoperative LN metastasis rate in our series was $64 \%$, which was higher than the published $23 \%{ }^{19}$ The recurrence rate in our series (30\%) was higher than that previously reported in published studies (10 to $20 \%),{ }^{18,20}$ which can mostly likely be attributed to differences in surgical techniques and treatments between different surgeons. However, the surgical management of

Table 3 Correlation of the preoperative lymph node status with recurrence risk

\begin{tabular}{|l|l|l|}
\hline $\begin{array}{l}\text { Preoperative radiologic } \\
\text { investigation }\end{array}$ & $\begin{array}{l}\text { No. of patients with } \\
\text { recurrence (\%) }\end{array}$ & $p$ Value \\
\cline { 1 - 2 } $\begin{array}{l}\text { Negative LN status on } \\
\text { US }(n=20)\end{array}$ & $6(30)$ & 0.778 \\
\cline { 1 - 2 } $\begin{array}{l}\text { Positive LN status on } \\
\text { US }(n=34)\end{array}$ & $12(35.3)$ & \multirow{2}{*}{0.01} \\
\cline { 1 - 2 } $\begin{array}{l}\text { Negative LN status on } \\
\text { CT }(n=15)\end{array}$ & $1(6.67)$ & \\
\hline $\begin{array}{l}\text { Positive LN status on } \\
\text { CT }(n=14)\end{array}$ & $10(62.5)$ & \\
\hline
\end{tabular}

Abbreviations: CT, computed tomography; LN, lymph node; US, ultrasonography.

${ }^{a}$ The chi-square test was used to measure $p$ values $(p<0.05$ was considered significant by Fisher's exact tests). 
Table 4 A comparison of the prognostic accuracy of radiologic modalities for predicting recurrence

\begin{tabular}{|l|l|l|l|l|l|}
\hline Modality & Sensitivity (\%) & Specificity (\%) & Accuracy (\%) & PPV (\%) & NPV (\%) \\
\hline US & 66.67 & 77.78 & 74 & 60 & 82.35 \\
\hline CT & 80 & 90 & 86.6 & 80 & 90 \\
\hline
\end{tabular}

Abbreviations: CT, computed tomography; NPV, negative predictive value; PPV, positive predictive value; US, ultrasonography.

malignant thyroid nodule was based on FNAC and frozen section evaluation, with the FNAC being more sensitive and cost-effective. ${ }^{21}$

In this study, we evaluated age, sex, tumor size, LN size, and US and CT findings preoperatively to determine the relationship of these factors with nodal recurrence. Univariate analysis has been used, due to small sample, although it was insufficient in comparison with multivariate analysis. Age and sex are considered prognostic factors (2010 AJCC staging system), ${ }^{17,22}$ but these factors were not associated with cervical recurrence in our study.

In addition, tumor size and $\mathrm{LN}$ size were not predictive of cervical recurrence. Preoperative LN metastasis was associated with locoregional recurrence, as has been described for other studies. ${ }^{18,23}$ In 560 Japanese patients with thyroid cancer who underwent total thyroidectomy, those with USdetectable metastasis had a significantly worse relapse-free survival than those with negative US findings. ${ }^{24}$ Hay et $\mathrm{al}^{25}$ and Spires et $\mathrm{a}^{26}$ showed that $\mathrm{LN}$ metastasis was related to a higher recurrence rate but did not adversely influence survival.

Our study and those mentioned previously would indicate that positive preoperative US findings for $\mathrm{LN}$ metastasis could indicate a more aggressive disease course and strongly predict the need for additional surgery in the future, whereas negative preoperative US LN findings indicate a lower risk with patients less likely to need future surgery. ${ }^{26}$ However, most importantly, we determined that preoperative detection of LN metastases with CT-based detection was significantly more specific, sensitive, and accurate than US-based detection; all patients who had negative preoperative CT LN metastasis findings remained recurrence-free, whereas 30\% of the patients with negative US LN metastases findings went on to develop locoregional recurrence. This strongly suggests that preoperative CT detection of LN metastases is a better modality for predicting locoregional recurrence in patients with DTC. On the other hand, the sensitivity and specificity of positive LN status on US in this study were less than those in other published studies. ${ }^{15,27,28}$

\section{Conclusions}

According to this study, patients with thyroid cancer with positive radiologic investigations (either US or CT) for LN metastasis have an increased risk of regional node recurrence after total thyroidectomy. CT was superior to US at detecting metastatic LN involvement, and, therefore, on the basis of our data, we suggest that $\mathrm{CT}$ should be further studied and considered as a more suitable alternative to US for preoperative evaluation and postoperative follow-up investigations.

\section{References}

1 Davies L, Welch HG. Increasing incidence of thyroid cancer in the United States, 1973-2002. JAMA 2006;295(18):2164-2167

2 Gilliland FD, Hunt WC, Morris DM, Key CR. Prognostic factors for thyroid carcinoma. A population-based study of 15,698 cases from the Surveillance, Epidemiology and End Results (SEER) program 1973-1991. Cancer 1997;79(3):564-573

3 Mazzaferri EL, Kloos RT. Clinical review 128: current approaches to primary therapy for papillary and follicular thyroid cancer. J Clin Endocrinol Metab 2001;86(4):1447-1463

4 Johnson NA, LeBeau SO, Tublin ME. Imaging surveillance of differentiated thyroid cancer. Radiol Clin North Am 2011;49(3): 473-487, vi

5 Cady B, Rossi R. An expanded view of risk-group definition in differentiated thyroid carcinoma. Surgery 1988;104(6):947-953

6 Hay ID, Thompson GB, Grant CS, et al. Papillary thyroid carcinoma managed at the Mayo Clinic during six decades (1940-1999): temporal trends in initial therapy and long-term outcome in 2444 consecutively treated patients. World J Surg 2002;26(8):879-885

7 Simon D, Goretzki PE, Witte J, Röher HD. Incidence of regional recurrence guiding radicality in differentiated thyroid carcinoma. World J Surg 1996;20(7):860-866, discussion 866

8 Mazzaferri EL, Jhiang SM. Long-term impact of initial surgical and medical therapy on papillary and follicular thyroid cancer. Am J Med 1994;97(5):418-428.Erratum in: Am J Med 1995;98:215

9 Pacini F, Molinaro E, Castagna MG, et al. Recombinant human thyrotropin-stimulated serum thyroglobulin combined with neck ultrasonography has the highest sensitivity in monitoring differentiated thyroid carcinoma. J Clin Endocrinol Metab 2003;88(8): 3668-3673

10 Schlumberger M, Berg G, Cohen O, et al. Follow-up of low-risk patients with differentiated thyroid carcinoma: a European perspective. Eur J Endocrinol 2004;150(2):105-112

11 Torlontano M, Crocetti U, Augello G, et al. Comparative evaluation of recombinant human thyrotropin-stimulated thyroglobulin levels, 131I whole-body scintigraphy, and neck ultrasonography in the follow-up of patients with papillary thyroid microcarcinoma who have not undergone radioiodine therapy. J Clin Endocrinol Metab 2006;91(1):60-63

12 Saggiorato E, Aversa S, Deandreis D, et al. Galectin-3: presurgical marker of thyroid follicular epithelial cell-derived carcinomas. J Endocrinol Invest 2004;27(4):311-317

13 Marshall CL, Lee JE, Xing Y, et al. Routine pre-operative ultrasonography for papillary thyroid cancer: effects on cervical recurrence. Surgery 2009;146(6):1063-1072

14 Greene FL, Page DL, Fleming ID, et al, eds. American Joint Committee on Cancer; American Cancer Society. AJCC Cancer Staging Manual. 6th ed. New York, NY: Springer-Verlag; 2002

15 González HE, Cruz F, O'Brien A, et al. Impact of preoperative ultrasonographic staging of the neck in papillary thyroid carcinoma. Arch Otolaryngol Head Neck Surg 2007;133(12): $1258-1262$ 
16 Shaha AR. Prognostic factors in papillary thyroid carcinoma and implications of large nodal metastasis. Surgery 2004;135(2):237-239

17 Shaha A. Treatment of thyroid cancer based on risk groups. J Surg Oncol 2006;94(8):683-691

18 Pacini F, Schlumberger M, Dralle H, Ilisea R, Smith Y, Viersinga V. [European consensus on the management of patients with differentiated carcinoma of the thyroid from follicular epithelium]. Vestn Khir Im I I Grek 2008;167(1):52-56[Article in Russian]

19 Londero SC, Krogdahl A, Bastholt L, et al; Danish Thyroid Cancer Group. Papillary thyroid microcarcinoma in Denmark 1996-2008: a national study of epidemiology and clinical significance. Thyroid 2013;23(9):1159-1164

20 Dionigi G, Dionigi R, Bartalena L, Boni L, Rovera F, Villa F. Surgery of lymph nodes in papillary thyroid cancer. Expert Rev Anticancer Ther 2006;6(9):1217-1229

21 Caraci P, Aversa S, Mussa A, Pancani G, Ondolo C, Conticello S. Role of fine-needle aspiration biopsy and frozen-section evaluation in the surgical management of thyroid nodules. Br J Surg 2002;89(6): 797-801

22 Schlumberger M, Pacini F, Wiersinga WM, et al. Follow-up and management of differentiated thyroid carcinoma: a European perspective in clinical practice. Eur J Endocrinol 2004;151(5): 539-548
23 Wada N, Masudo K, Nakayama H, et al. Clinical outcomes in older or younger patients with papillary thyroid carcinoma: impact of lymphadenopathy and patient age. Eur J Surg Oncol 2008;34(2): 202-207

24 Ito Y, Tomoda C, Uruno T, et al. Ultrasonographically and anatomopathologically detectable node metastases in the lateral compartment as indicators of worse relapse-free survival in patients with papillary thyroid carcinoma. World J Surg 2005;29(7): 917-920

25 Hay ID, Grant CS, van Heerden JA, Goellner JR, Ebersold JR, Bergstralh EJ. Papillary thyroid microcarcinoma: a study of 535 cases observed in a 50-year period. Surgery 1992;112(6): 1139-1146, discussion 1146-1147

26 Spires JR, Robbins KT, Luna MA, Byers RM. Metastatic papillary carcinoma of the thyroid: the significance of extranodal extension. Head Neck 1989;11(3):242-246

27 Poehls JL, Chen H, Sippel RS. Preoperative ultrasonography findings predict the need for repeated surgery in papillary thyroid cancer. Endocr Pract 2012;18(3):403-409

28 Roh JL, Park JY, Kim JM, Song CJ. Use of preoperative ultrasonography as guidance for neck dissection in patients with papillary thyroid carcinoma. J Surg Oncol 2009;99(1): 28-31 